Review

\title{
Biomimetic Membranes for Multi-Redox Center Proteins
}

\author{
Renate L. C. Naumann *, Andreas F. Geiss, Christoph Steininger and Wolfgang Knoll \\ Austrian Institute of Technology GmbH, AIT, Donau-City-Str. 1, 1220 Vienna, Austria; \\ andreas.geiss.fl@ait.ac.at (A.F.G.); christoph.steininger.fl@ait.ac.at (C.S.); Wolfgang.Knoll@ait.ac.at (W.K.) \\ * Correspondence: kontakt@rlc-naumann.eu; Tel.: +49-6151-44669
}

Academic Editor: Bernhard Schuster

Received: 7 September 2015; Accepted: 17 February 2016; Published: 3 March 2016

\begin{abstract}
His-tag technology was applied for biosensing purposes involving multi-redox center proteins (MRPs). An overview is presented on various surfaces ranging from flat to spherical and modified with linker molecules with nitrile-tri-acetic acid (NTA) terminal groups to bind his-tagged proteins in a strict orientation. The bound proteins are submitted to in situ dialysis in the presence of lipid micelles to form a so-called protein-tethered bilayer lipid membrane (ptBLM). MRPs, such as the cytochrome c oxidase $(\mathrm{C} C \mathrm{O})$ from $R$. sphaeroides and P. denitrificans, as well as photosynthetic reactions centers (RCs) from $R$. sphaeroides, were thus investigated. Electrochemical and surface-sensitive optical techniques, such as surface plasmon resonance, surface plasmon-enhanced fluorescence, surface-enhanced infrared absorption spectroscopy (SEIRAS) and surface-enhanced resonance Raman spectroscopy (SERRS), were employed in the case of the ptBLM structure on flat surfaces. Spherical particles ranging from $\mu \mathrm{m}$ size agarose gel beads to $\mathrm{nm}$ size nanoparticles modified in a similar fashion were called proteo-lipobeads (PLBs). The particles were investigated by laser-scanning confocal fluorescence microscopy (LSM) and UV/Vis spectroscopy. Electron and proton transfer through the proteins were demonstrated to take place, which was strongly affected by the membrane potential. MRPs can thus be used for biosensing purposes under quasi-physiological conditions.
\end{abstract}

Keywords: multi-redox center proteins; protein-tethered bilayer lipid membrane; cytochrome c oxidase; photosynthetic reaction centers; surface-enhanced infrared absorption spectroscopy; surface-enhanced resonance Raman spectroscopy; laser-scanning confocal microscopy; UV/Vis spectroscopy; his-tag technology; proteo-lipobeads

\section{Introduction}

Biosensing based on multi-redox center proteins (MRP) has often been performed on solubilized proteins. The most prominent example of this approach is protein film voltammetry [1,2]. Important information about the electrochemical properties of proteins has thus been obtained. The methods of preparation were mostly the immobilization of micelles. Similar methods have often been applied for use with FTIR spectroscopy. Proteins were immobilized on the surface of an ATR crystal via detergent depletion, drying and rehydration [3]. A large body of valuable information has been assembled, but uncertainties remain as to whether the proteins maintain their full functionality under these conditions. Therefore, designing biomimetic membrane systems on surfaces has been attempted, which would be suitable to entrap MRPs into a functionally active bilayer lipid membrane (BLM) [4,5].

The oriented immobilization of MRPs on surfaces modified with nitrile-tri-acetic acid (NTA) via his-tag technology has proved to be very auspicious in this context, particularly if the immobilization was followed by in situ dialysis in the presence of lipid micelles. The proteins are thereby incorporated into a BLM to form what was called a protein-tethered bilayer lipid membrane (ptBLM) [6,7]. The system was later employed by other groups to investigate MRPs such as membrane photoreceptors 
and complex I from E. coli $[8,9]$, whereas we concentrated on the cytochrome $c$ oxidase $(\mathrm{CcO})$ from $R$. sphaeroides. The protein was genetically engineered with his-tags attached to subunit II. In this configuration, the first electron acceptor $\mathrm{Cu}_{\mathrm{A}}$ points toward the electrode so that the enzyme can be activated by direct electron transfer (ET) [10]. The $\mathrm{C} c \mathrm{O}$ was investigated via fast scan voltammetry and electrochemical titration followed by surface-enhanced infrared absorption spectroscopy (SEIRAS) and surface-enhanced resonance Raman spectroscopy (SERRS) [11-13]. The enzyme could be shown to undergo conformational changes through the uptake of four electrons and to translocate protons across the membrane [14]. These results prompted us to conduct time-resolved tr-SEIRAS on this and other proteins, such as the reaction centers (RCs) and the $b c_{1}$ complex of photosynthetic bacteria.

Moreover, we made attempts to expand the range of methodologies applicable to MRPs incorporated in lipid membranes from vibrational to fluorescence and UV/Vis spectroscopies. In this context, we exchanged flat surfaces versus particles from $\mu \mathrm{m}$ sized gel beads down to nanoparticles. The concept of the ptBLM was thus shown to be applicable also to particle surfaces.

Hence we have demonstrated that the concept of the ptBLM offers the advantage of the immobilization of MRPs in a strict orientation on various surfaces, an important feature if it comes to the investigation of transport parameters. Hence a particular MRP can be induced to transport ions and/or electrons outside-in or inside-out of the BLM, provided the MRP is available with his-tags attached to either side of the protein. This was available to us in the case of the $\mathrm{CcO}$ and the photosynthetic reaction centers from $R$. sphaeroides and P. denitrificans, respectively. Pros and cons of the different approaches are discussed.

\section{Results and Discussion}

\subsection{Multi-Redox Center Proteins Immobilized on Planar Surfaces}

The most advanced techniques applicable to proteins on planar surfaces are surface-enhanced IR and Raman spectroscopies. The surfaces are enhanced by nano-structures such as nanoparticles (NPs) attached to the plane surface that modulate the electromagnetic field around them. The enhancement comes about by the excitation of localized surface plasmon resonances (LSPR), which are electromagnetic waves that enhance the electromagnetic (EM) field near the metallic nanostructures $[15,16]$. This EM field rapidly decreases into the liquid phase so that only molecules a few nm away from the metallic surface are affected. A review on surface-enhanced Raman spectroscopy for biomedical diagnostics and imaging can be found in ref. [17]. The theory of SEIRAS and SERRS comprises the high sensitivity of bands whose components are located at a short distance from the surface but also the surface selection rule, which predicts that adsorbed molecules are reflected the stronger the more the transition dipole moment is oriented perpendicular to the surface $[16,18]$. This means that a component may be presented only in one orientation whereas other orientations are not represented. We had previously developed two-layer gold and silver surfaces with NPs generated in situ that were suitable to apply not only electrochemical techniques but also SEIRAS and SERRS to our ptBLM structures. $\mathrm{C} c \mathrm{O}$ incorporated into a ptBLM had thus been investigated by fast scan voltammetry and electrochemical titration followed SEIRAS as well as SERRS [11-13]. The same surface was then employed to perform time-resolved tr-SEIRAS [19].

\subsubsection{Time Resolved tr-SEIRAS of Cytochrome $c$ Oxidase $(\mathrm{CcO})$ from R. sphaeroides}

$\mathrm{CcO}$ with a his-tag engineered to the $\mathrm{C}$ terminus of subunit II was immobilized on the surface of the silicon ATR crystal of an IR spectrometer, covered with a structured gold film. On top of the ATR crystal, a flow cell was mounted and filled with a buffer solution appropriate for the immobilization and subsequent reconstitution into a ptBLM using in situ dialysis. Tr-SEIRAS was performed in the step-scan mode under anaerobic conditions by applying periodic potential pulses stepping between -800 and $+400 \mathrm{mV}$ at a modulation frequency of $100 \mathrm{~Hz}$ [19]. 
As a result, a broad band was obtained in the region of the amide I bands (Figure 1), which, however, contained many overlapping bands, as revealed by a treatment called phase sensitive detection (PSD) (Figure 2A) [20]. PSD allowed us to subtract a large water band at $1643 \mathrm{~cm}^{-1}$ which otherwise would have obscured the bands of the secondary structures. The absorbance of this band was determined independently by measuring a SEIRA spectrum of a droplet of water on top of a Ni-NTA modified nano-structured gold surface. Details can be found in the supplementary information of reference [19]. Figure 2A shows PSD-deconvoluted tr-SEIRA spectra. The band areas obtained from Figure 2A were plotted as a function of time; see examples in Figure 2B-D used for the fitting routine, all of which are negative bands. The negative sign means they represent reduced species, which gradually disappear in the first half period of the potential pulse, going from -800 to $+400 \mathrm{mV}$, and re-appear in the second half period, from +400 to $-800 \mathrm{mV}$. The bands located at 1603,1610 and $1625 \mathrm{~cm}^{-1}$, assigned to $\mathrm{Cu}_{\mathrm{A}}$, heme $a$, and heme $a_{3}$, respectively, were selected to be fitted to the kinetic model of the $\mathrm{CcO}$, which is described below and in detail in reference [21,22]. See also Figure 3.

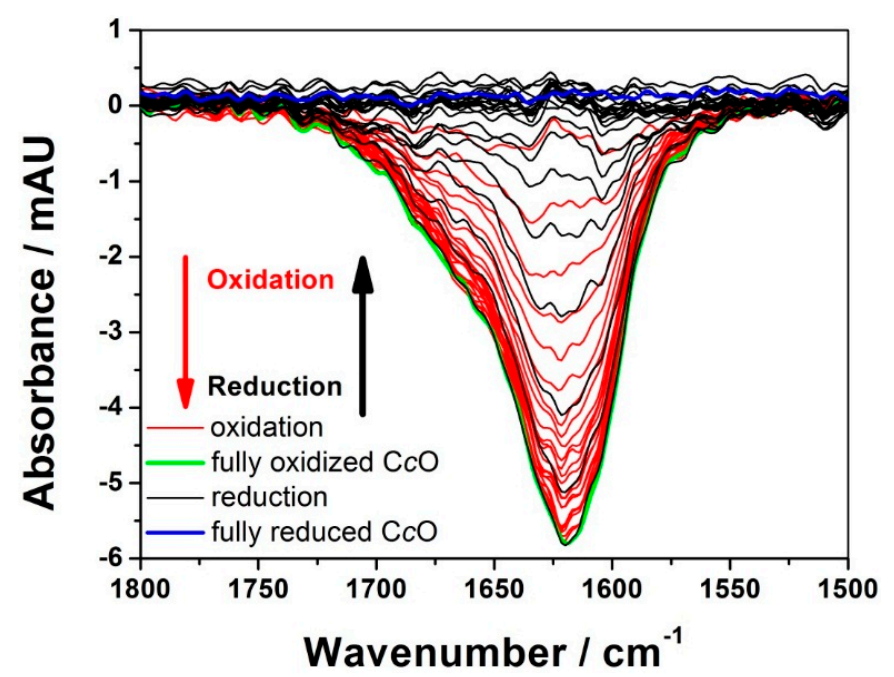

Figure 1. Time-resolved surface-enhanced infrared absorption spectroscopy (tr-SEIRAS) spectra of the activated cytochrome $c$ oxidase $(\mathrm{CcO})$ under anaerobic conditions. Spectra of the first excitation half period (oxidation) are shown in red, and those of the second half period (reduction) are shown in black. Spectra were taken over time intervals of $200 \mu$ s. Reproduced with permission from Schwaighofer et al. (2013) [19].
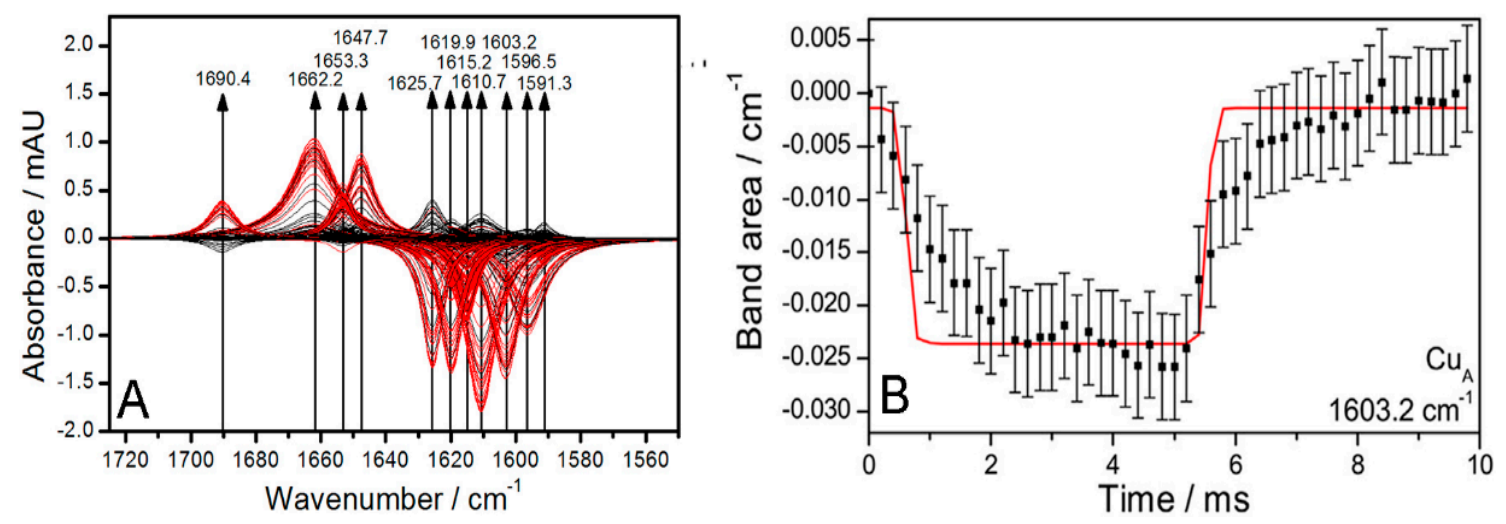

Figure 2. Cont. 

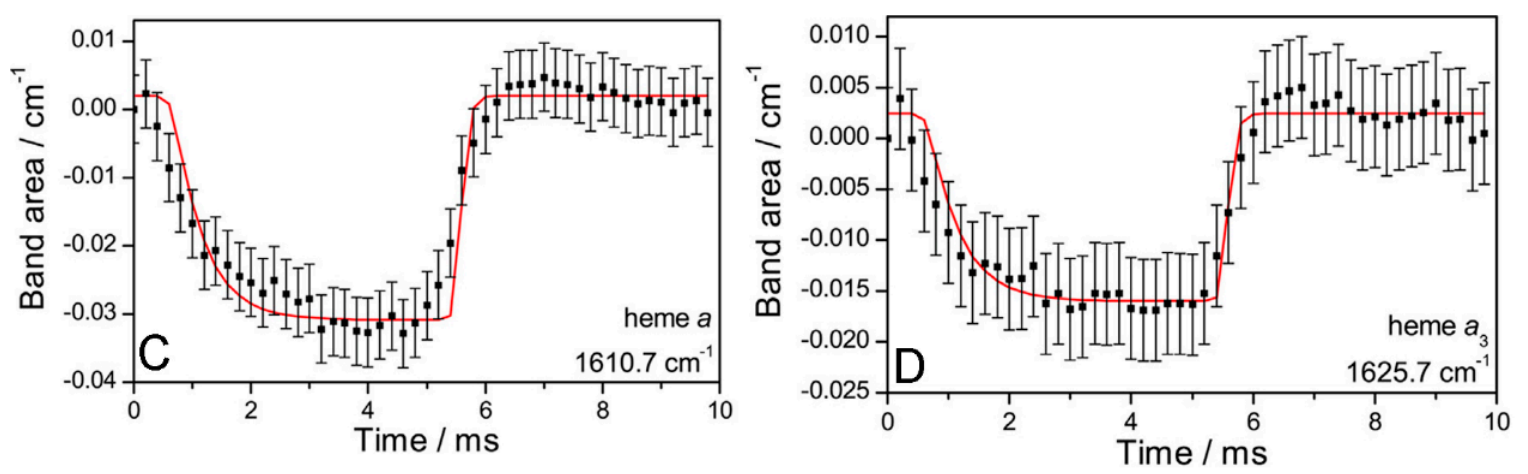

Figure 2. (A) Simulated spectra of deconvoluted bands revealed by phase sensitive detection (PSD) at an excitation frequency of $100 \mathrm{~Hz}$. Subtraction of the $\mathrm{OH}$ bending band reveals positive and negative bands that are attributed to oxidized and reduced species, respectively. Spectra obtained in the first and second excitation half periods are shown in red and black, respectively; (B-D) Plots of band areas vs. time (black squares) of the bands at $1603.2\left(\mathrm{Cu}_{\mathrm{A}}\right), 1610.7$ (heme $a$ ) and $1625.7 \mathrm{~cm}^{-1}$ (heme $\left.a_{3}\right)$. The fitted curves of band areas $v s$. time to the sequential four-electron transfer model of cytochrome $c$ oxidase $(\mathrm{CcO})$ are given as solid red lines. Reproduced with permission from Schwaighofer et al. (2013) [19].

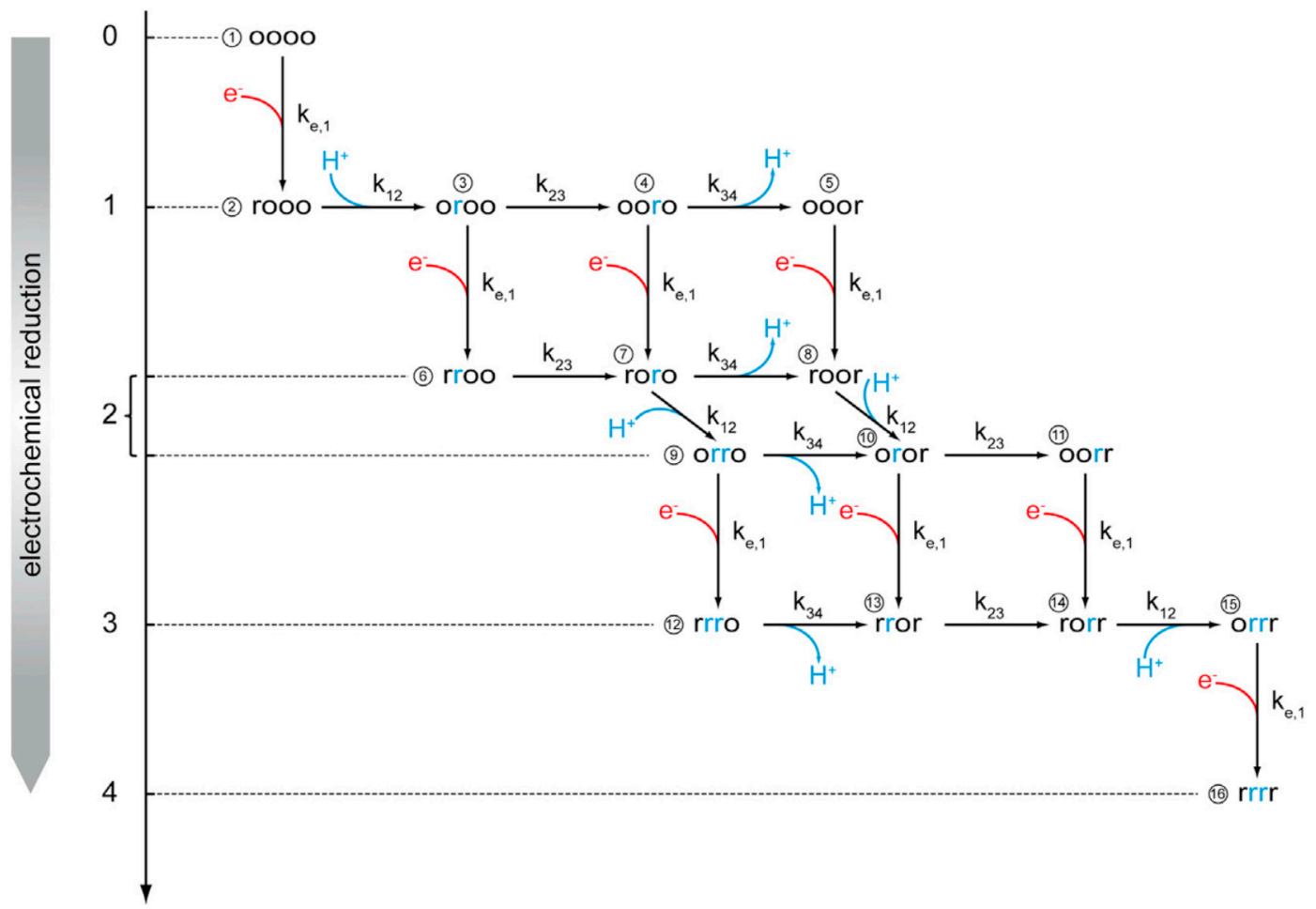

Figure 3. Kinetic scheme for sequential electron transfer in $\mathrm{CcO}$ under anaerobic conditions. The four centers are arranged in the order $\mathrm{Cu}_{\mathrm{A}}$, heme $a$, heme $a_{3}$, and $\mathrm{Cu}_{\mathrm{B}}$, which can be present either in the reduced $(\mathrm{r})$ or oxidized (o) state. All of the $\mathrm{r}$ and o states can be protonated or deprotonated. Hence, the enzyme can exist in 16 different redox states and 256 protonation states. The vertical arrows with red branches represent electron uptake from the electrode, whereas the black horizontal arrows indicate second-order reactions between redox centers. The blue arrows indicate proton uptake and release steps likely to occur as a consequence of the second-order ET reactions between redox centers. Reproduced with permission from Schwaighofer et al. (2013) [19].

The same bands were found as in our titration study, although the distribution between the two types of secondary structures was quite different. In the titration, the helical structures are more 
prominent, while in the tr-SEIRA spectra the $\beta$-sheets are more strongly represented (see the bands at $1603,1615,1619,1625 \mathrm{~cm}^{-1}$ ) while the band at $1653 \mathrm{~cm}^{-1}$, which is characteristic for $\alpha$-helices, is weak in comparison. These findings agree well with the higher flexibility of $\beta$-sheets found in molecular dynamics (MD) studies of high-resolution crystallographic structures [23,24]. The greater rigidity of the $\alpha$-helices, on the other hand, prevents these structures from following the excitation at high modulation frequencies, resulting in a lower absorbance in the respective IR-signals. Substantial conformational changes were also recently observed in separate high-resolution crystallography images of the reduced and oxidized form of $\mathrm{CcO}$ [25]. Bands at 1603.2, 1610.7 and $1625.7 \mathrm{~cm}^{-1}$ were assigned to changes in the redox state of $\mathrm{Cu}_{\mathrm{A}}$, heme $a$, and heme $a_{3}$, respectively.

The time-resolved absorbances of these bands were fitted to a kinetic model of proton transport through $\mathrm{CcO}$ (Figure 2). In this model, we use chemical reaction kinetics to explore proton transport coupled to electron transport (ET) in terms of a sequence of protonation-dependent second-order redox reactions, first presented in reference [21]. We thereby assume fixed rather than shifting dissociation constants of the redox sites. A schematic of the model is shown in Figure 3.

Bayesian inference was used to obtain the set of parameters that achieved the best agreement of experimental and simulated data. As fitting parameters, we chose the inherently $\mathrm{pH}$-independent standard redox potentials and the $\mathrm{pK}$ values of the four redox centers in the order of sequential ET: $\mathrm{Cu}_{\mathrm{A}}$, heme $a$, heme $a_{3}$, and $\mathrm{Cu}_{\mathrm{B}}$. As for the kinetic parameters, we must distinguish between electrochemical ET to $\mathrm{Cu}_{\mathrm{A}}$, which is characterized by the electrochemical rate constant, and the chemical reaction kinetics between consecutive redox centers. Finally, $\tau$, the time constant of charging the interface also has to be included. The kinetic constants of reactions between consecutive redox centers were found to be in the ms time scale and limited by electrochemical excitation. For further details, we refer to the original publication [19].

In this investigation, direct ET to a selected redox center of an MRP has thus been demonstrated to mimic the natural pathway of electrons through the enzyme. Electrochemical excitation has been shown as an alternative to the photolytic $\mathrm{CO}$ dissociation otherwise used to initiate enzyme turnover. The kinetics of enzyme reduction and oxidation, however, is limited by the ET rate to the electrode.

Later, we extended these studies to other multi-redox center proteins such as light-activated photosynthetic reaction centers from Rhodobacter sphaeroides.

\subsubsection{Photosynthetic Reaction Centers from R. sphaeroides}

Reaction centers (RCs) with 7-his tags attached to the C-terminus of the M-subunit were reconstituted into a ptBLM as described. In this configuration, the special pair $\mathrm{P} / \mathrm{P}+$ is directed toward the gold film, whereas the $\mathrm{Q}_{\mathrm{A}}$ and $\mathrm{Q}_{\mathrm{B}}$ sites are directed toward the aqueous phase, and the ubiquinone pool is freely mobile within the lipid bilayer. As a further benefit, additional liposoluble $\mathrm{Q}_{10}$ can be co-reconstituted in controlled quantities. The formation of the entire structure was followed by electrochemical impedance (EIS) and SEIRA spectroscopy because the thin gold film can also be used as an electrode [26].

\section{Light Activation of Reaction Centers (RCs) Followed by SEIRAS}

In this configuration, light-minus-dark SEIRA spectra were measured while the RCs were excited by continuous illumination under a halogen lamp first without any additional $\mathrm{Q}_{10}$. The term "light-minus-dark spectra" means that these are difference spectra that use spectra in the dark as references, which are subtracted from the spectra under illumination. A small number of prominent bands appeared, increasing over time in a time scale of minutes (Figure 4). 


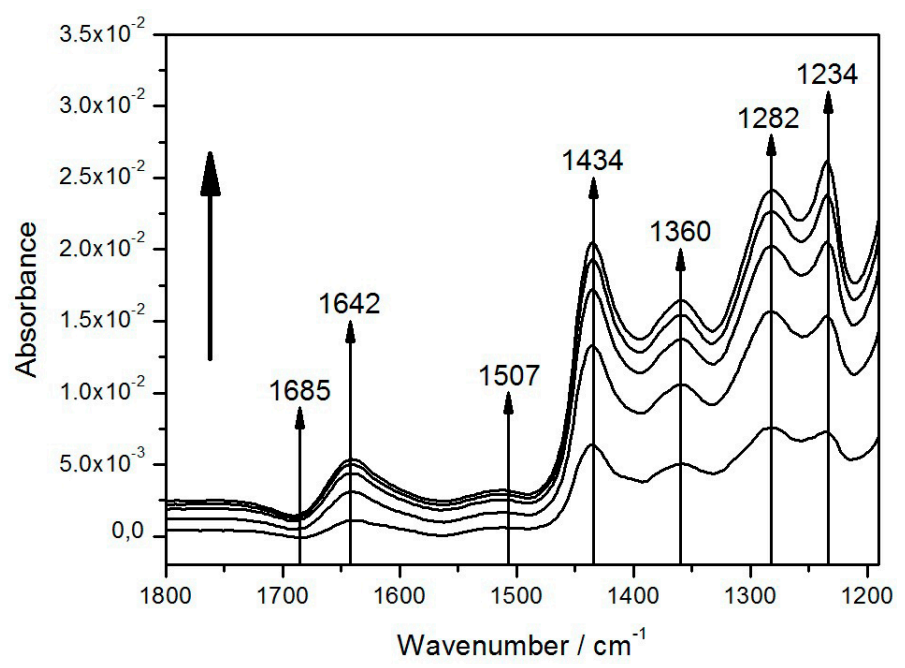

Figure 4. Light-minus-dark absorption spectra of reaction centers (RCs) encapsulated in the protein-tethered bilayer lipid membrane (ptBLM) taken at $5 \mathrm{~min}$ time intervals without added $\mathrm{Q}_{10}$ under continuous illumination. The term "light-minus-dark spectra" means that these are difference spectra using the spectra in the dark as references, which are subtracted from the spectra under illumination. The spectra were recorded every $5 \mathrm{~min}$. Reproduced with permission of Nedelkovski et al. (2013) [26].

A steady state was not attained within a time scale of seconds as in previous investigations $[27,28]$. Nevertheless, the bands shown in our spectra could be correlated with characteristic groups found in previous studies. The tentative assignment of bands is shown in Table 1. The most prominent of these bands (1282 and $1434 \mathrm{~cm}^{-1}$ ) could be assigned to the oxidized form of the primary electron donor or special pair of the $\mathrm{RC}, \mathrm{P}^{+}$, and ubihydroquinone, $\mathrm{QH}_{2}$, respectively, the products of light activation of the RCs. This was a surprising result, because in previous studies, appreciable amounts of $\mathrm{QH}_{2}$ could only be attained in the presence of an artificial electron donor, such as ascorbate $\mathrm{P}^{+}$, as it was reduced back to the reduced form of the special pair, $\mathrm{P}$ [29].

Table 1. Tentative band assignments of SEIRAS spectra of RCs encapsulated in the ptBLM recorded under continuous illumination [26]. Reproduced with permission of Nedelkovski et al. [26].

\begin{tabular}{cccc}
\hline \multicolumn{2}{c}{ Band $\left(\mathbf{c m}^{-1}\right)$} & \multicolumn{2}{c}{ Tentative Assignment } \\
\hline Experimental & Literature & Species & Component \\
\hline 1282 & 1282 & $\mathrm{P}^{+}$ & $($complex $)$ \\
1360 & 1355,1365 & $\mathrm{Q}_{\mathrm{A}}$ & $-\mathrm{CH}_{3}$ \\
1434 & 1433 & $\mathrm{QH}_{2}$ & \\
1643 & $1640,1641,1642[31]$ & quinone $\mathrm{Q}, \mathrm{Q}_{\mathrm{B}}$ & $\mathrm{C}=\mathrm{O}$ \\
1685 & 1682,1683 & 9-keto group of $\mathrm{P}$ & $\mathrm{C}=\mathrm{O}$ \\
3400 & 3485 & $\mathrm{Q}_{\mathrm{B}}^{-} / \mathrm{Q}_{\mathrm{B}}$ or $\mathrm{P}^{+}$ & $\mathrm{H}_{2} \mathrm{O}$ \\
3629 & 3632 & $\mathrm{Q}_{\mathrm{B}}-/ \mathrm{Q}_{\mathrm{B}}$ or $\mathrm{P}^{+}$ & $\mathrm{H}_{2} \mathrm{O}$ \\
\hline
\end{tabular}

The growth of the band areas was fully reversible, when the light was switched off, as shown in Figure 5B. Most band areas are reduced in the course of the relaxation with the exception of the bands at 1234 and $1685 \mathrm{~cm}^{-1}$, which are restored. This unexpected behavior combines several features characteristic for the SEIRA spectra of the ptBLM. Above all, the general pattern of the spectra is obviously different from the pattern of FTIR difference spectra usually displayed in the literature, which is mostly composed of narrow peaks and troughs [30]. 

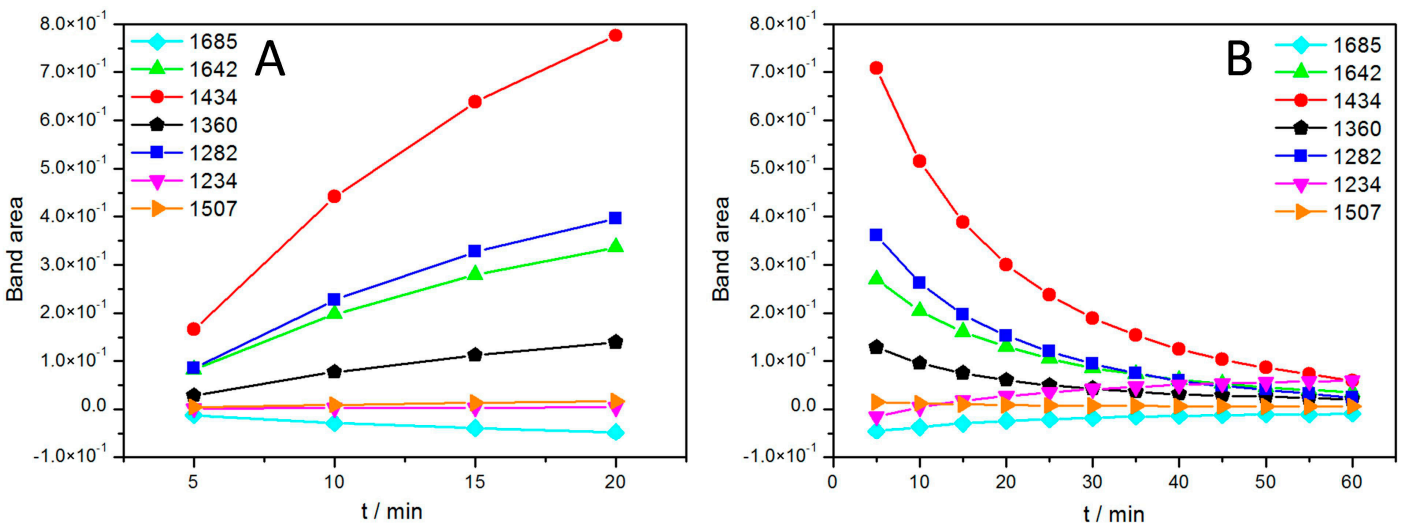

Figure 5. Band areas of the absorbances of characteristic bands of the RCs in the ptBLM under continuous illumination taken at different time intervals with added $Q_{10}$ when the light is switched on (A) and off (B), i.e., during relaxation. Reproduced with permission of Nedelkovski et al. (2013) [26].

The effect was even more pronounced when additional $Q_{10}$ was co-reconstituted. The evolution of band amplitudes over time in the presence of additional $Q_{10}$ is shown in Figure 5.

The reduced number of bands in the SEIRA spectra can be explained in terms of the surface selection rule, which comprises the high sensitivity of only those bands whose components are located at a short distance from the surface and the dependency of the sensitivity from the orientation of the transition dipole moments. The sensitivity is higher the more the component is oriented perpendicular to the surface $[16,18]$. According to this rule it depends on the orientation of a component whether it is strongly represented or not at all. This explains why the same functional group is represented by a certain band whereas other bands are missing. e.g., $\mathrm{QH}_{2}$ is usually represented by the bands $1434,1491,1470 \mathrm{~cm}^{-1}$, but only the band at $1434 \mathrm{~cm}^{-1}$ is definitively seen. This effect is amplified by the pre-orientation of the MRP molecules on the surface. Moreover, most of the bands appear to point in one direction, as seen in Figure $2 \mathrm{~A}(\mathrm{CcO})$ and Figure $3(\mathrm{RC})$. In the case of the $\mathrm{CcO}$, this directionality can be explained by the superposition by the large water band. After subtraction, the bands point in both directions. In the case of the RC, all the bands are positive except for the $1685 \mathrm{~cm}^{-1}$ band, which is consistent with the fact that they represent products of the illumination. The only exception is the ground state of $\mathrm{P}$, which is an educt. Another specific feature of the SEIRA spectra can be seen in the relatively large full width at half maximum (FWHM) of the bands, as compared to the sharp bands found in FTIR spectra of molecules present on the surface in a random orientation [30].The FWHM is associated with the freedom of movement of the particular structure represented by the component [32]. In previous studies, proteins were investigated mostly with redox mediators present. In our SEIRAS titration study of cytochrome $c$ oxidase, we recorded a marked minimizing of the FWHMs in the presence of mediators $[11,13]$. This effect might be explained by the difference in internal dipole moments of the activated protein after the redox sites had been equilibrated with the mediators.

Irrespective of these general features of the SEIRA spectra, the slow evolution of species such as $\mathrm{P}^{+}$and $\mathrm{QH}_{2}$, found in the case of the $\mathrm{RC}$, is unexpected. In previous FTIR work, the release of $\mathrm{QH}_{2}$ from its binding pocket and its replacement by a quinone molecule from the quinone pool has been observed under the continuous illumination of chromatophores from R. sphaeroides, but only in the presence of ascorbate or other compounds to reduce $\mathrm{P}^{+}$back to $\mathrm{P}$ [29]. The slow generation of species such as $\mathrm{QH}_{2}$ (and/or $\mathrm{Q}_{\mathrm{B}} \mathrm{H}_{2}$ ) and $\mathrm{P}^{+}$, in the absence of an electron donor, can be explained by the reaction between two excited molecules of the RC.

$$
\mathrm{P}^{+} \mathrm{Q}_{\mathrm{B}}^{-}+\mathrm{P}^{+} \mathrm{Q}_{\mathrm{B}}^{-} \rightarrow \mathrm{P}^{+} \mathrm{Q}_{\mathrm{B}}+\mathrm{P}^{+} \mathrm{Q}_{\mathrm{B}}^{2-}
$$

followed by protonating $\mathrm{Q}_{\mathrm{B}}{ }^{2-}$, releasing $\mathrm{QH}_{2}$ into the membrane and then rebinding $\mathrm{Q}_{\mathrm{B}}$ from the quinone pool. The model is supported by the fact that all of the light-induced SEIRA bands exhibit 
similar kinetics. Further support is derived from by the reversal of the original disproportion during relaxation (Figure 5B):

$$
2 \mathrm{P}^{+} \mathrm{Q}_{\mathrm{B}}+\mathrm{QH}_{2} \rightarrow \mathrm{P}^{+} \mathrm{Q}_{\mathrm{B}}^{2-}+\mathrm{P}^{+} \mathrm{Q}_{\mathrm{B}} \rightarrow \mathrm{P}^{+} \mathrm{Q}_{\mathrm{B}}^{-}+\mathrm{P}^{+} \mathrm{Q}_{\mathrm{B}}^{-}
$$

Thus, this study has demonstrated that inter-protein reactions are possible when the MRP is incorporated into the ptBLM. SEIRA spectra were again shown to be dominated by the surface selection rule, whose effects are strongly enhanced by the strict orientation of the protein perpendicular to the surface.

\section{Direct Electron Transfer to Photosynthetic Reaction Centers from R. sphaeroides}

The RCs were immobilized into a ptBLM as described above, with a genetically engineered 7-his tag at the $\mathrm{C}$-terminus of the $\mathrm{M}$-subunit such that the primary electron donor (the special pair $\mathrm{P}$ ) was directed toward the gold electrode, in this case a smooth gold electrode. After illumination, $\mathrm{P}$ is converted into the oxidized species $\mathrm{P}^{+}$. Direct electron transfer (ET) to $\mathrm{P}^{+}$was investigated, particularly in the context of generating photocurrents [33].

A very similar system had previously been introduced by the group of Lebedev and Trammel [34-36], who used linker molecules of different lengths to immobilize RCs on gold electrodes via his-tag technology, but without reconstitution into a ptBLM. Photocurrents were recorded in the range of $\mathrm{nA}$ after illumination of the RCs, but only when the photocurrents were mediated by cytochrome $c(\mathrm{cc})$ and ubiquinone-2 (Q2). In our attempt to repeat these measurements in the presence of the BLM, we found dramatically different behavior. Substantial photocurrents lasting for more than $15 \mathrm{~min}$ in the range of $\mu \mathrm{A}$ were obtained in the cathodic direction in the range of negative potentials with an optimum at $-200 \mathrm{mV}$. Photocurrents were even larger in the presence of the ptBLM (Figure 6) but not appreciably affected by the mediators Q2 and cc.

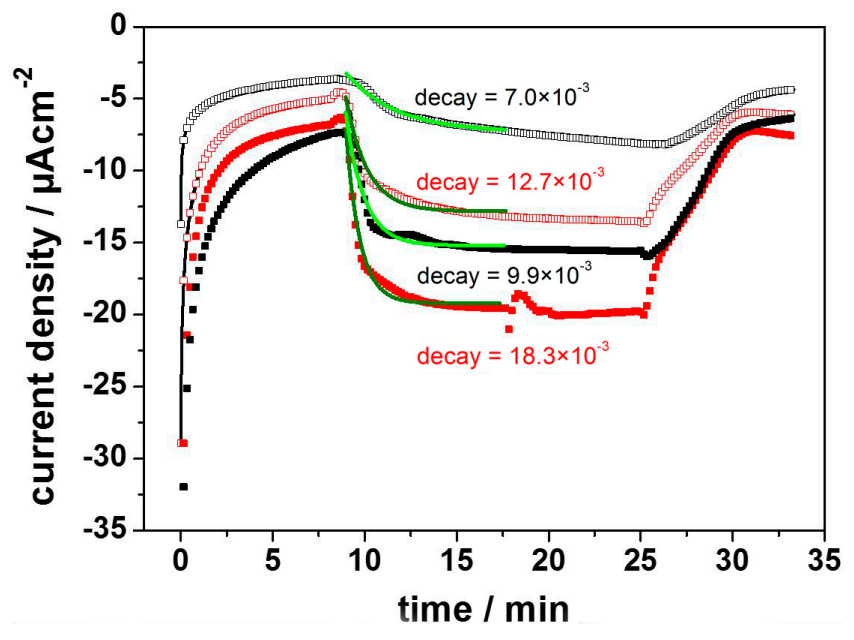

Figure 6. Photocurrents of RCs immobilized on a nitrilo-tri-acetic acid (NTA) modified template stripped gold (TSG) measured before (black) and after (red) formation of the ptBLM, at $-200 \mathrm{mV}$ (open squares) and $-300 \mathrm{mV}$ (full squares). Green lines are the monoexponential fits of the data. Reproduced with permission of Gebert et al. (2015) [33].

These comparatively high photocurrents were explained in terms of the disproportionation reaction (Equation (1)) discussed above. The direct electron transfer was attributed to the species $\mathrm{P}^{+} \mathrm{Q}_{\mathrm{B}}$ rather than $\mathrm{P}^{+}$. This is consistent with the fact that we did not detect the photocurrents found by Trammel et al. at potentials of approximately $0 \mathrm{mV}$. We conclude that the photocurrents measured at -200 and $-300 \mathrm{mV}$ are due to direct $\mathrm{ET}$ to the species $\mathrm{P}^{+} \mathrm{Q}_{\mathrm{B}}$. The corresponding oxidation peak is 
again between +600 and $+650 \mathrm{mV}$, which can be explained in terms of the electrochemical reduction of $\mathrm{P}^{+} \mathrm{Q}_{\mathrm{B}}$, which restores the ground state of the RC primary donor.

In summary, photocurrents of remarkable magnitude and stability have been generated, amplified by an inter-protein reaction in addition to the usual high energy conversion efficiency in RCs.

\subsection{From Flat Surfaces to Particles}

Flat surfaces are well designed for the application of electrochemical and surface-enhanced techniques such as surface plasmon resonance, surface plasmon-enhanced fluorescence and vibrational spectroscopies. Localized fluorescence effects, however, are not easily accessible on flat surfaces. Methods such as laser scanning confocal microscopy (LSM) are more suitable for 3D particles. Therefore, we transferred the ptBLM technique to commercially available particles of different sizes from $\mu \mathrm{m}$ down to $\mathrm{nm}$, modified with NTA-terminated linkers. We referred to the obtained structures as proteo-lipobeads (PLBs) (Figure 7).

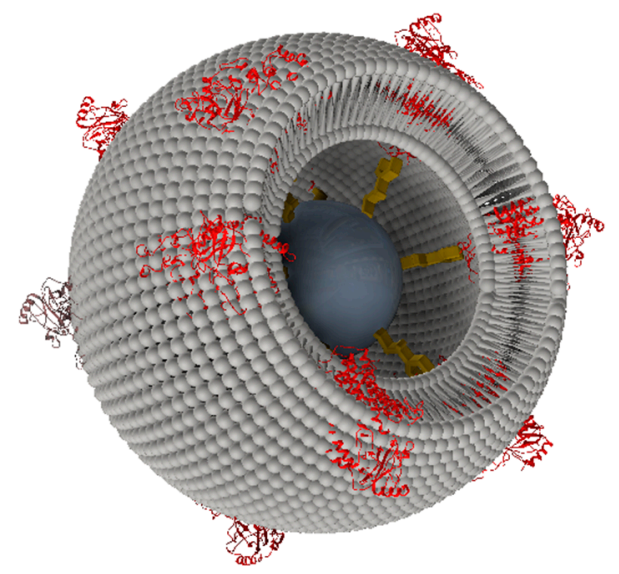

Figure 7. A schematic view of a proteo-lipobead (PLB). The agarose or silica bead is shown in dark grey, the NTA-terminated linker in yellow and the $\mathrm{CcO}$ in red, which is bound to the NTA-linker via a his-tag attached to the cytoplasmically oriented C-terminus of subunit I. The lipid bilayer is shown in light grey. The layered structure is not drawn to scale. Reproduced with permission of Frank et al. (2015) [37].

2.2.1. Cytochrome $c$ Oxidase from P. denitrificans Incorporated in Proteo-Lipobeads (PLBs) Based on Agarose Beads

$\mathrm{C} c \mathrm{O}$ from Paracoccus denitrificans with a his-tag engineered to the $\mathrm{C}$-terminus of the subunit I was bound to agarose beads (HisPur Ni-NTA Resin, 50-150 $\mu \mathrm{m}$, Thermo Scientific, Schwerte, Germany), followed by in situ dialysis in the presence of lipid micelles to form PLBs [37].

The formation of the lipid layer was demonstrated by LSM, employing fluorescence-labeled lipids such as 1,2-dihexadecanoyl-sn-glycero-3-phospho-(N-4-nitrobenz-2-oxa-1,3-diazolyl)ethanolamine (NBD-PE) and the potential-sensitive dyes di-8-ANEPPS (di-8-butyl-amino-naphtyl-ethylenepyridinium-propyl-sulfonate) and the red-shifted dye di-4-ANBDQBS (4-(1-[2-(di-n-butylamino)-6naphthyl]-4-butadienyl)-1-(4-butylsulfonate) quinolinium betaine) (Figure 8). Hemicyanine-based membrane probes, such as di-8-ANEPPS and di-4-ANBDQBS, fluoresce strongly when bound to BLMs whereas they exhibit negligible fluorescence in aqueous solution [38]. Figure 8 illustrates a BLM layer with regular fluorescence intensity around the bead.

In the configuration above, the $\mathrm{cc}$ binding site of the $\mathrm{CcO}$ is pointing toward the outside of the PLB. Hence proton transport can be initiated by photoactive electron donors such as the Ru complex $\mathrm{Ru}_{2} \mathrm{C}\left(\left[(\mathrm{bpy})_{2} \mathrm{Ru}(\right.\right.$ diphen $\left.\left.) \mathrm{Ru}(\mathrm{bpy})_{2}\right]\left(\mathrm{PF}_{6}\right)_{4}\right)$, which after light-activation acts as an electron donor, bound to the $c c$ binding site. $\mathrm{Ru}_{2} \mathrm{C}$ was mixed with aniline as a sacrificial electron donor and $3 \mathrm{CP}$ (3-carboxy-PROXYL) to prevent proton release from the aniline [39]. The $\mathrm{pH}$ changes 
at the outer surface of the PLB were detected by fluorescein DHPE (1-(8-(( $3^{\prime}, 6^{\prime}$-dihydroxy-3-oxospiro(isobenzofuran-1(3H), 9'-(9H)xanthen)-5-yl)amino)-3-hydroxy-8-thioxo-2,4-dioxa-7-aza-3-phosphaoct1-yl)-1,2-ethanediyl ester, P-oxide), a sensor molecule that incorporates into the distal leaflet of the lipid bilayer. The decrease in fluorescence intensity indicates a decrease in $\mathrm{pH}$ in the outer solution. The fluorescence intensities were measured after continuous illumination with a halogen lamp with and without a mixture of $\mathrm{Ru}_{2} \mathrm{C}, 3 \mathrm{CP}$ and aniline. Fluorescence intensities decreased to an extent of $10 \%$ and $42 \%$ of the initial value in the buffered and unbuffered $\mathrm{KCl}$ solution, respectively. No decrease was observed in the presence of valinomycin and FCCP (carbonyl cyanide 4-(trifluoromethoxy)phenylhydrazone), i.e., under uncoupling conditions. The intensity decreased to $55 \%$ of the initial value with only valinomycin present, which is explained by the collapse of the membrane potential (Figure 9). This behavior is in accordance with an active transporter controlled by the membrane potential.

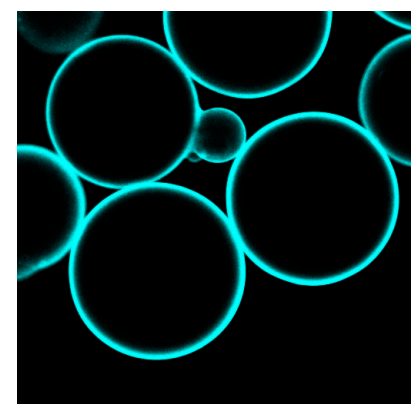

Figure 8. Confocal laser scanning microscopy (LSM) images of PLBs based on agarose beads. PLBs are labeled with the potential-sensitive dye di-4-ANBDQBS (4-(1-[2-(di-n-butylamino)-6naphthyl]-4-butadienyl)-1-(4-butylsulfonate) quinolinium betaine). Reproduced with permission of Frank et al. (2015) [37].
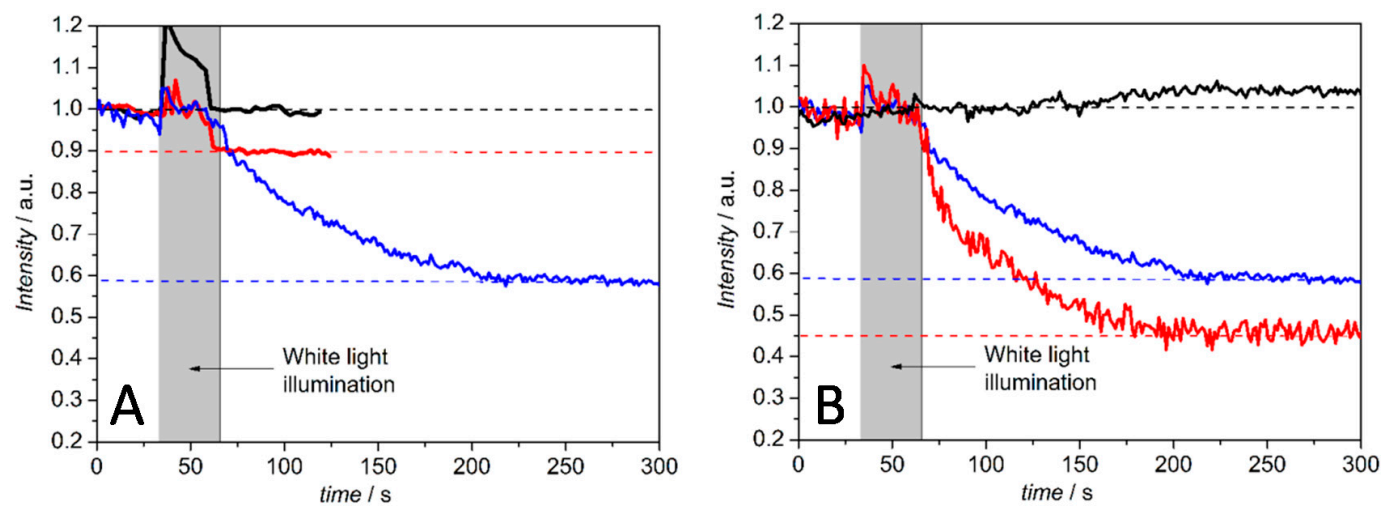

Figure 9. Change in the relative fluorescence intensity of membrane-bound $\mathrm{pH}$-sensitive fluorescein DHPE ((1-(8-((3',6'-dihydroxy-3-oxo-spiro(isobenzofuran-1(3H), 9'-(9H)xanthen)-5-yl)amino)-3-hydroxy8-thioxo-2,4-dioxa-7-aza-3-phosphaoct-1-yl)-1,2-ethanediyl ester, P-oxide) over time, before and after continuous illumination with a halogen lamp. (A) Comparison of unbuffered $(40 \mathrm{mM} \mathrm{KCl})$ (blue) and buffered ( $35 \mathrm{mM} \mathrm{KCl}, 5 \mathrm{mM}$ Tris- $\mathrm{HCl}$ ) (red) PLB solutions, each of them containing $\mathrm{Ru}_{2} \mathrm{C}$ ([(bpy) ${ }_{2} \mathrm{Ru}$ (diphen) $\left.\left.\mathrm{Ru}(\mathrm{bpy})_{2}\right]\left(\mathrm{PF}_{6}\right)_{4}\right), 3 \mathrm{CP}$ (3-carboxy-PROXYL) and aniline to enable light excitation, and buffered PLB solution without the Ru2C, 3CP and aniline (black); (B) Change in the relative fluorescence intensity of $\mathrm{pH}$-sensitive membrane bound fluorescein DHPE over time, before and after continuous illumination with a halogen lamp with $\mathrm{Ru}_{2} \mathrm{C}, 3 \mathrm{CP}$ and aniline in a $40 \mathrm{mM} \mathrm{KCl}$ solution (blue), in the presence of valinomycin alone (red) and with both valinomycin and FCCP (carbonyl cyanide 4-(trifluoromethoxy)phenylhydrazone) (black). The $\mathrm{pH}$ was adjusted to 8 before all measurements. Reproduced with permission of Frank et al. (2015) [37]. 
2.2.2. Cytochrome $c$ Oxidase from P. denitrificans Incorporated in PLBs Based on Silica Nanoparticles

The size of the agarose beads $(50-150 \mu \mathrm{m})$ described above, is very well suited for the application of LSM. However, they are not designed for the application of optical spectroscopy because they would suffer from serious interferences by light scattering of the particles. Therefore, we used commercially available $25 \mathrm{~nm}$ sized Ni-NTA-modified silica nanoparticles (NPs) to prepare PLBs designed for $\mathrm{UV} /$ Vis measurements [40].

Particle size was measured by dynamic light scattering in the course of PLB preparation, starting with the NPs before and after $\mathrm{CcO}$ binding and after incorporation of the lipid bilayer. The size distribution increases regularly from 25 to 40 and $50 \mathrm{~nm}$, for the NPs, the proteobeads and the PLBs, respectively (Figure 10). This increase is in accordance with crystallographic data for $\mathrm{CcO}$, which predicts a height of $12 \mathrm{~nm}$ in the upright position [41].

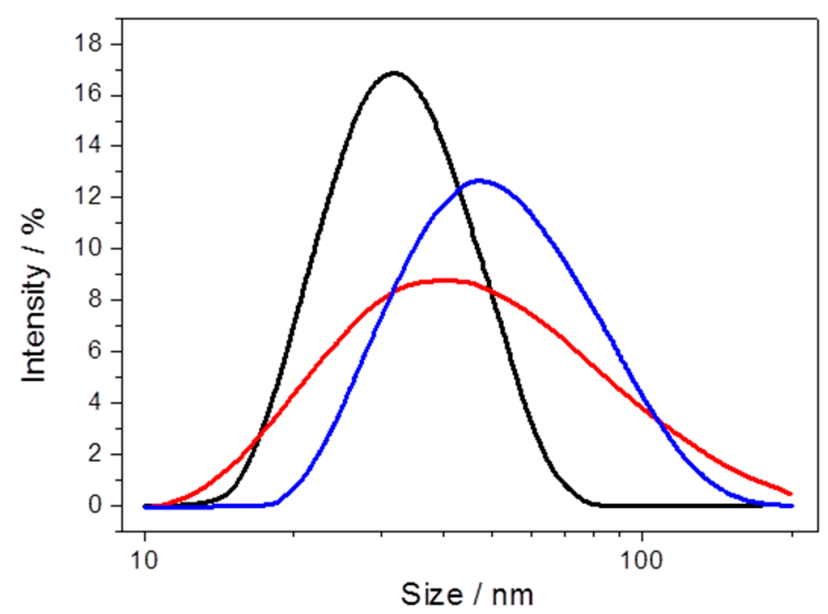

Figure 10. Particle size of PLBs, measured by dynamic light scattering of Ni-NTA-functionalized nanoparticles (NPs) (black), after $\mathrm{CcO}$ binding (red) and after dialysis (blue). Reproduced with permission of Schadauer et al. (2015) [40].

$\mathrm{UV} /$ Vis spectra of $\mathrm{CcO}$ solubilized and $\mathrm{CcO}$ encapsulated in PLBs, before and after reduction with dithionite are shown in Figure 11. Light scattering effects are indicated by a sloping baseline, particularly at lower wavelengths. However, there is no interference of light scattering with the spectroscopic bands used for the determination of the concentrations of $\mathrm{CcO}$, obtained using an extinction coefficient $\varepsilon_{606-630 \mathrm{~nm}}^{\text {reduced-oxidied }}=23.4 \mathrm{mM}^{-1} \cdot \mathrm{cm}^{-1}$ [42].
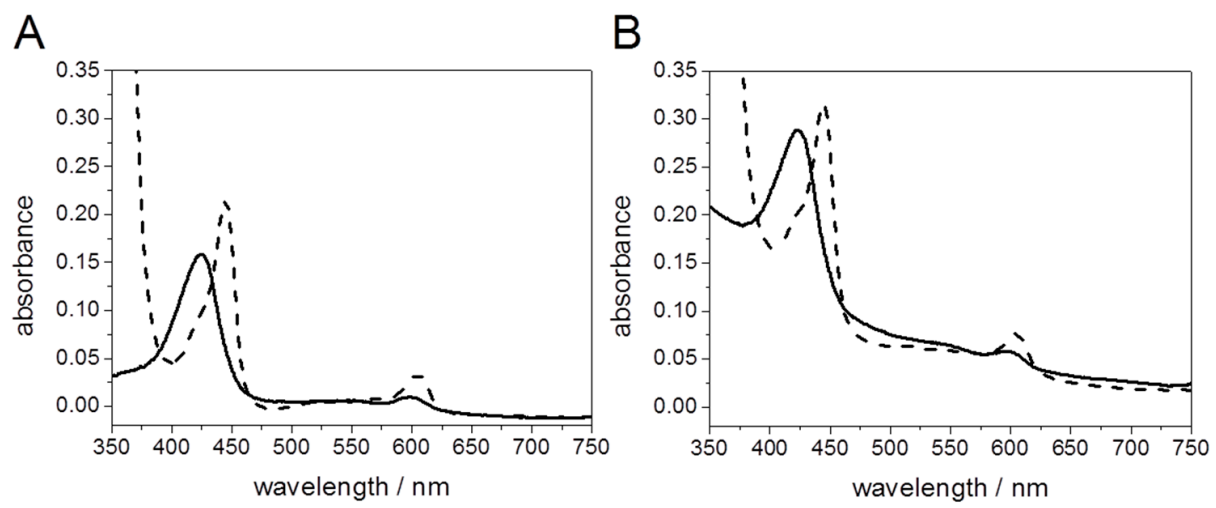

Figure 11. UV/Vis spectra of solubilized $\mathrm{CcO}(\mathbf{A})$ and $\mathrm{PLB}$-bound $\mathrm{CcO}(\mathbf{B})$ oxidized with potassium ferricyanide (solid line) and reduced with sodium hydrosulfite (dashed line), respectively, at a $\mathrm{CcO}$ concentration of $1.1 \mu \mathrm{M}$. Reproduced with permission of Schadauer et al. (2015) [40]. 
The activity of the incorporated $\mathrm{CcO}$ was assessed using a model based on the Michaelis-Menten equation. To this end, the reaction of the enzyme with reduced $c c$ was followed, using solubilized $\mathrm{CcO}$ as well as the protein incorporated in proteobeads and PLBs. The measurements of the PLBs were also performed with $0.5 \mu \mathrm{M}$ valinomycin and $1.2 \mu \mathrm{M}$ FCCP present. The initial rates plotted against the $c c$ concentration were fitted to the Michaelis-Menten equation. Fit parameters were the turnover number, $k_{\text {cat }}$, and the substrate affinity, $K_{\mathrm{M}}$. The kinetic constants are collected in Table 2.

Table 2. Kinetic parameters derived from Michaelis-Menten kinetics for $\mathrm{CcO}$ incorporated in PLBs. Reproduced with permission of Schadauer et al. (2015) [40].

\begin{tabular}{ccccc}
\hline \multirow{2}{*}{ Parameter } & \multirow{2}{*}{ ccO, Solubilized } & \multirow{2}{*}{$\begin{array}{c}\mathrm{C} \text { O } \text {, in } \\
\text { Proteobeads }\end{array}$} & \multicolumn{2}{c}{ CcO, in PLBs } \\
\cline { 3 - 5 } & & & - Val./FCCP & +Val./FCCP \\
\hline$K_{\mathrm{M}}(\mu \mathrm{M})$ & $5.8 \pm 0.4$ & $1.6 \pm 0.4$ & $2.6 \pm 0.4$ & $2.7 \pm 0.6$ \\
$k_{\mathrm{cat}}\left(\mathrm{s}^{-1}\right)$ & $264.1 \pm 7.4$ & $32.4 \pm 0.5$ & $11.9 \pm 0.8$ & $33.4 \pm 8.8$ \\
Number of preparations & & 3 & 3 & 3 \\
Number of measurements & 3 & 3 & 3 & 3 \\
\hline
\end{tabular}

$k_{\text {cat }}=264 \mathrm{~s}^{-1}$ of solubilized $\mathrm{CcO}$ was found to reflect literature values [43]. It was found to decrease to a $k_{\text {cat }}=32$ and $11 \mathrm{~s}^{-1}$ for proteobeads and PLBs, respectively. $k_{\text {cat }}$ of $\mathrm{CcO}$ incorporated in PLBs recovered in the presence of valinomycin and FCCP to $k_{\text {cat }}=33 \mathrm{~s}^{-1}$. The reduction of $k_{\text {cat }}=32 \mathrm{~s}^{-1}$ was considered as being due to the immobilization of the proteins. The further reduction to $k_{\text {cat }}=11 \mathrm{~s}^{-1}$ within the PLBs was considered in terms of the lipid membrane. This conclusion seems justified in view of $k_{\text {cat }}=33 \mathrm{~s}^{-1}$ found under uncoupling conditions. From these values, the respiratory control ratio (RCR), was calculated to be 2.8. This is well in accordance with the RCR of 2.7 observed in proteo-liposomes [44]. The binding constant $K_{\mathrm{M}}=5.8 \mu \mathrm{M}$ of solubilized $\mathrm{CcO}$ was found to agree with literature data [43]. It decreased to 1.6 and $2.6 \mu \mathrm{M}$ for proteobeads and PLBs, respectively. Summarizing, $\mathrm{CcO}$ within the PLBs suffers from a drastic decrease in activity, however, exhibiting improved binding properties.

\section{Conclusions}

These results demonstrate that the ptBLM structure is useful as a tool for biosensing. The main advantage of the ptBLM over traditional systems such as solubilized proteins or proteoliposomes is the strict orientation of the proteins embedded in the lipid bilayer. Other methods may be feasible in this context, such as electrostatic or antibody binding. Antibodies, however, usually have much larger dimensions compared with the combined his-tag and NTA-linkers. Hence, the proteins under investigation would be located outside the region of the evanescent wave of the EM field and thus would not be amenable to surface enhancement techniques such as SEIRAS and SERRS. Larger distances between the electrode and protein would also seriously hinder direct ET, which is relevant, for example, in the context of photocurrents. Electrostatic binding, on the other hand, is not as specific as his-tag binding. Moreover, purified proteins are now generally available genetically engineered with his-tags.

A method particularly well designed for use with ptBLMs is SEIRA spectroscopy. Electrochemical and light activation can be easily applied in a periodic fashion so that high quality $\mathrm{S} / \mathrm{N}$ ratios can be easily obtained in tr-FTIR measurements. The surface selection rule, which works in favor of certain vibrations while others are silenced, presents a drawback. This feature, however, may actually be an advantage if the orientation of certain secondary structures is an aspect of interest. In any case, conformational changes in secondary structures with time can be observed, which is an important issue, particularly because time-dependent X-ray spectroscopy is not yet available.

The ptBLMs may also be considered for biosensing MRP inhibitors. They are frequently applied as herbicides because of their function as inhibitors, for example against complex III of the respiratory chain. There is high interest in biosensing these compounds with high sensitivity and selectivity. 
The ptBLMs are not only significant in the context of biosensing but also in the context of basic research. We have strong evidence that under the conditions described here, the natural pathway of electrons all the way through the protein is maintained, particularly in the case of the $\mathrm{CcO}$.

As for the methods to be applied, ptBLMs on flat surfaces allow the application of external electric fields and surface sensitive techniques such as surface plasmon resonance, surface plasmon-enhanced fluorescence and vibrational spectroscopies. PLBs based on spherical particles, on the other hand, allow for fluorescence microscopy and classical UV/Vis measurements. Fluorescence methods applied to PLBs open the way to bioassays for screening purposes including high-throughput screening. Hence, a whole range of methods is available to study MRPs under nearly physiological conditions.

Acknowledgments: We are grateful to Bernhard Schuster, University of Natural Resources and Life Sciences, Vienna, for his valuable support in our attempts at patch clamp measurements.

Author Contributions: This is a review article written by Renate L. C. Naumann and Wolfgang Knoll. Andreas F. Geiss and Christoph Steininger did the graphics and proof reading and literature research.

Conflicts of Interest: The authors declare no conflict of interest.

\section{References}

1. Jeuken, L.J.C. Electrodes for integral membrane enzymes. Nat. Prod. Rep. 2009, 26, 1234-1240. [CrossRef] [PubMed]

2. Armstrong, F.A. Insights from protein film voltammetry into mechanisms of complex biological electron-transfer reactions. J. Chem. Soc. Dalton Trans. 2002. [CrossRef]

3. Gorbikova, E.A.; Belevich, N.P.; Wikstrom, M.; Verkhovsky, M.I. Time-resolved ATR-FTIR spectroscopy of the oxygen reaction in the D124N mutant of cytochrome $c$ oxidase from Paracoccus denitrificans. Biochemistry 2007, 46, 13141-13148. [CrossRef] [PubMed]

4. Tanaka, M.; Sackmann, E. Polymer-supported membranes as models of the cell surface. Nature 2005, 437, 656-663. [CrossRef] [PubMed]

5. Terrettaz, S.; Mayer, M.; Vogel, H. Highly electrically insulating tethered lipid bilayers for probing the function of ion channel proteins. Langmuir 2003, 19, 5567-5569. [CrossRef]

6. Giess, F.; Friedrich, M.G.; Heberle, J.; Naumann, R.L.; Knoll, W. The protein-tethered lipid bilayer: A novel mimic of the biological membrane. Biophys. J. 2004, 87, 3213-3220. [CrossRef] [PubMed]

7. Ataka, K.; Giess, F.; Knoll, W.; Naumann, R.; Haber-Pohlmeier, S.; Richter, B.; Heberle, J. Oriented attachment and membrane reconstitution of his-tagged cytochrome $c$ oxidase to a gold electrode: In situ monitoring by surface-enhanced infrared absorption spectroscopy. J. Am. Chem. Soc. 2004, 126, 16199-16206. [CrossRef] [PubMed]

8. Jiang, X.; Zaitseva, E.; Schmidt, M.; Siebert, F.; Engelhard, M.; Schlesinger, R.; Ataka, K.; Vogel, R.; Heberle, J. Resolving voltage-dependent structural changes of a membrane photoreceptor by surface-enhanced IR difference spectroscopy. Proc. Natl. Acad. Sci. USA 2008, 105, 12113-12117. [CrossRef] [PubMed]

9. Kriegel, S.; Uchida, T.; Osawa, M.; Friedrich, T.; Hellwig, P. Biomimetic environment to study E-coli complex I through surface-enhanced IR absorption spectroscopy. Biochemistry 2014, 53, 6340-6347. [CrossRef] [PubMed]

10. Friedrich, M.G.; Robertson, J.W.F.; Walz, D.; Knoll, W.; Naumann, R.L.C. Electronic wiring of a multi-redox site membrane protein in a biomimetic surface architecture. Biophys. J. 2008, 94, 3698-3705. [CrossRef] [PubMed]

11. Nowak, C.; Santonicola, M.G.; Schach, D.; Zhu, J.P.; Gennis, R.B.; Ferguson-Miller, S.; Baurecht, D.; Walz, D.; Knoll, W.; Naumann, R.L.C. Conformational transitions and molecular hysteresis of cytochrome $c$ oxidase: Varying the redox state by electronic wiring. Soft Matter 2010, 6, 5523-5532. [CrossRef]

12. Nowak, C.; Schach, D.; Gebert, J.; Grosserueschkamp, M.; Gennis, R.B.; Ferguson-Miller, S.; Knoll, W.; Walz, D.; Naumann, R.L.C. Oriented immobilization and electron transfer to the cytochrome c oxidase. J. Solid State Electrochem. 2011, 15, 105-114. [CrossRef]

13. Nowak, C.; Laredo, T.; Gebert, J.; Lipkowski, J.; Gennis, R.B.; Ferguson-Miller, S.; Knoll, W.; Naumann, R.L.C. 2D-SEIRA spectroscopy to highlight conformational changes of the cytochrome $c$ oxidase induced by direct electron transfer. Metallomics 2011, 3, 619-627. [CrossRef] [PubMed] 
14. Naumann, R.L.C.; Nowak, C.; Knoll, W. Proteins in biomimetic membranes: Promises and facts. Soft Matter 2011, 7, 9535-9548. [CrossRef]

15. Hexter, R.M.; Albrecht, M.G. Metal surface Raman spectroscopy: Theoriy. Spectrochim. Acta A 1979, 35, 233-251. [CrossRef]

16. Moskovits, M. Surface roughness and the enhanced intensity of Raman scattering by molecules adsorbed on metals. J. Chem. Phys. 1978, 69, 4159-4161. [CrossRef]

17. Srajer, J.; Schwaighofer, A.; Nowak, C. Surface-enhanced Raman spectroscopy for biomedical diagnostics and imaging. Biomed. Spectrosc. Imaging 2013, 2, 51-71.

18. Osawa, M. Surface-enhanced infrared absorption. Near Field Opt. Surf. Plasmon. Polaritons 2001, 81, $163-187$.

19. Schwaighofer, A.; Steininger, C.; Hildenbrandt, D.M.; Srajer, J.; Nowak, C.; Knoll, W.; Naumann, R.L.C. Time-resolved surface-enhanced IR-absorption spectroscopy of direct electron transfer to cytochrome c oxidase from R. sphaeroides. Biophys. J. 2013, 105, 2706-2713. [CrossRef] [PubMed]

20. Schwaighofer, A.; Ferguson-Miller, S.; Naumann, R.L.C.; Knoll, W.; Nowak, C. Phase-sensitive detection in modulation excitation spectroscopy applied to potential induced electron transfer in cytochrome $c$ oxidase. Appl. Spectrosc. 2014, 68, 5-13. [CrossRef] [PubMed]

21. Srajer, J.; Schwaighofer, A.; Hildenbrandt, D.M.; Kibrom, A.; Naumann, R.L.C. A kinetic model of proton transport in a multiredox centre protein: Cytochrome $c$ oxidase. Prog. React. Kinet. Mech. 2013, 38, 32-47. [CrossRef]

22. Schach, D.; Nowak, C.; Gennis, R.B.; Ferguson-Miller, S.; Knoll, W.; Walz, D.; Naumann, R.L.C. Modeling direct electron transfer to a multi-redox center protein: Cytochrome $c$ oxidase. J. Electroanal. Chem. 2010, 649, 268-276. [CrossRef]

23. Buhrow, L.; Ferguson-Miller, S.; Kuhn, L.A. From static structure to living protein: Computational analysis of cytochrome $c$ oxidase main-chain flexibility. Biophys. J. 2012, 102, 2158-2266. [CrossRef] [PubMed]

24. Liu, J.A.; Qin, L.; Ferguson-Miller, S. Crystallographic and online spectral evidence for role of conformational change and conserved water in cytochrome oxidase proton pump. Proc. Natl. Acad. Sci. USA 2011, 108, 1284-1289. [CrossRef] [PubMed]

25. Ferguson-Miller, S.; Hiser, C.; Liu, J. Gating and regulation of the cytochrome c oxidase proton pump. Biochim. Biophys. Acta Bioenerg. 2012, 1817, 489-494. [CrossRef] [PubMed]

26. Nedelkovski, V.; Schwaighofer, A.; Wraight, C.A.; Nowak, C.; Naumann, R.L.C. Surface-enhanced infrared absorption spectroscopy (SEIRAS) of light-activated photosynthetic reaction centers from Rhodobacter sphaeroides reconstituted in a biomimetic membrane system. J. Phys. Chem. 2013, 117, 16357-16363.

27. Breton, J. Steady-state FTIR spectra of the photoreduction of $\mathrm{Q}_{\mathrm{A}}$ and $\mathrm{Q}_{\mathrm{B}}$ in Rhodobacter sphaeroides reaction centers provide evidence against the presence of a proposed transient electron acceptor $\mathrm{X}$ between the two quinones. Biochemistry 2007, 46, 4459-4465. [CrossRef] [PubMed]

28. Mezzetti, A.; Leibl, W. Investigation of ubiquinol formation in isolated photosynthetic reaction centers by rapid-scan Fourier transform IR spectroscopy. Eur. Biophys. J. Biophys. Lett. 2005, 34, 921-936. [CrossRef] [PubMed]

29. Mezzetti, A.; Leibl, W.; Breton, J.; Nabedryk, E. Photoreduction of the quinone pool in the bacterial photosynthetic membrane: Identification of infrared marker bands for quinol formation. FEBS Lett. 2003, 537, 161-165. [CrossRef]

30. Mezzetti, A.; Blanchet, L.; de Juan, A.; Leibl, W.; Ruckebusch, C. Ubiquinol formation in isolated photosynthetic reaction centres monitored by time-resolved differential FTIR in combination with 2D correlation spectroscopy and multivariate curve resolution. Anal. Bioanal. Chem. 2011, 399, 1999-2014. [CrossRef] [PubMed]

31. Brudler, R.; Gerwert, K. Step-scan FTIR spectroscopy resolves the $Q_{A}{ }^{-} Q_{B} \rightarrow Q_{A} Q_{B}{ }^{-}$transition in Rb-sphaeroides R26 reaction centres. Photosynth. Res. 1998, 55, 261-266. [CrossRef]

32. Arrondo, J.L.R.; Castresana, J.; Valpuesta, J.M.; Goni, F.M. Structure and thermal-denaturation of crystalline and noncrystalline cytochrome-oxidase as studied by infrared-spectroscopy. Biochemistry 1994, 33, 11650-11655. [CrossRef] [PubMed]

33. Gebert, J.; Reiner-Rozman, C.; Steininger, C.; Nedelkovski, V.; Nowak, C.; Wraight, C.; Naumann, R.L.C. Electron Transfer to Light-Activated Photosynthetic Reaction Centers from Rhodobacter sphaeroides Reconstituted in a Biomimetic Membrane System. J. Phys. Chem. C 2015, 119, 890-895. [CrossRef] 
34. Lebedev, N.; Trammell, S.A.; Spano, A.; Lukashev, E.; Griva, I.; Schnur, J. Conductive wiring of immobilized photosynthetic reaction center to electrode by cytochrome c. J. Am. Chem. Soc. 2006, 128, 12044-12045. [CrossRef] [PubMed]

35. Trammell, S.A.; Griva, I.; Spano, A.; Tsoi, S.; Tender, L.M.; Schnur, J.; Lebedev, N. Effects of distance and driving force on photoinduced electron transfer between photosynthetic reaction centers and gold electrodes. J. Phys. Chem. C 2007, 111, 17122-17130. [CrossRef]

36. Trammell, S.A.; Wang, L.Y.; Zullo, J.M.; Shashidhar, R.; Lebedev, N. Orientated binding of photosynthetic reaction centers on gold using Ni-NTA self-assembled monolayers. Biosens. Bioelectron. 2004, 19, 1649-1655. [CrossRef] [PubMed]

37. Frank, P.; Siebenhofer, B.; Hanzer, T.; Geiss, A.F.; Schadauer, F.; Reiner-Rozman, C.; Durham, B.; Loew, L.M.; Ludwig, B.; Richter, O.M.H.; et al. Proteo-lipobeads for the oriented encapsulation of membrane proteins. Soft Matter 2015, 11, 2906-2908. [CrossRef] [PubMed]

38. Fluhler, E.; Burnham, V.G.; Loew, L.M. Spectra, membrane binding, and potentiometric responses of new charge shift probes. Biochemistry 1985, 24, 5749-5755. [CrossRef] [PubMed]

39. Belevich, I.; Bloch, D.A.; Belevich, N.; Wikstrom, M.; Verkhovsky, M.I. Exploring the proton pump mechanism of cytochrome c oxidase in real time. Proc. Natl. Acad. Sci. USA 2007, 104, 2685-2690. [CrossRef] [PubMed]

40. Schadauer, F.; Geiss, A.F.; Srajer, J.; Siebenhofer, B.; Frank, P.; Reiner-Rozman, C.; Ludwig, B.; Richter, O.M.; Nowak, C.; Naumann, R.L.C. Silica nanoparticles for the oriented encapsulation of membrane proteins into artificial bilayer lipid membranes. Langmuir 2015, 31, 2511-2516. [CrossRef] [PubMed]

41. Tihova, M.; Tattrie, B.; Nicholls, P. Electron-microscopy of cytochrome-c oxidase-containing proteoliposomes-Imaging analysis of protein orientation and monomer-dimer behavior. Biochem. J. 1993, 292, 933-946. [CrossRef] [PubMed]

42. Ludwig, B.; Schatz, G. A two-subunit cytochrome $c$ oxidase (cytochrome aa3) from Paracoccus dentrificans. Proc. Natl. Acad. Sci. USA 1980, 77, 196-200. [CrossRef] [PubMed]

43. Witt, H.; Zickermann, V.; Ludwig, B. Site-directed mutagenesis of cytochrome $c$ oxidase reveals 2 acidic residues involved in the binding of cytochrome c. Biochim. Biophys. Acta Bioenerg. 1995, 1230, 74-76. [CrossRef]

44. Nordlund, G.; Ng, J.B.S.; Bergstrom, L.; Brzezinski, P.A. Membrane-reconstituted multisubunit functional proton pump on mesoporous silica particles. ACS Nano 2009, 3, 2639-2646. [CrossRef] [PubMed]

(C) 2016 by the authors; licensee MDPI, Basel, Switzerland. This article is an open access article distributed under the terms and conditions of the Creative Commons by Attribution (CC-BY) license (http://creativecommons.org/licenses/by/4.0/). 